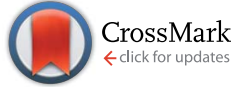

Cite this: J. Mater. Chem. A, 2014, 2 , 18463

Received 1st July 2014

Accepted 2nd September 2014

DOI: $10.1039 / \mathrm{c} 4 \mathrm{ta0} 3359 \mathrm{k}$

www.rsc.org/MaterialsA

\section{Thin film fabrication and characterization of proton conducting lanthanum tungstate $\dagger$}

\author{
Kristin Bergum, ${ }^{\star}$ Anna Magrasó, Helmer Fjellvåg and Ola Nilsen
}

Thin films of the proton conducting lanthanum tungstate phase, $\mathrm{La}_{28-x} \mathrm{~W}_{4+x} \mathrm{O}_{54+\delta} \mathrm{V}_{2-\delta}$, were fabricated by atomic layer deposition (ALD) and characterized by impedance spectroscopy. The films were prepared by combining the processes of deposition of $\mathrm{La}_{2} \mathrm{O}_{3}$ and $\mathrm{WO}_{3}$ using $\left[\mathrm{La}(\text { thd })_{3}+\mathrm{O}_{3}\right]$ and $\left[\left({ }^{\mathrm{t}} \mathrm{BuN}\right)_{2}\left(\mathrm{Me}_{2} \mathrm{~N}\right)_{2} \mathrm{~W}(\mathrm{vI})+\right.$ $\mathrm{H}_{2} \mathrm{O}$ ]. Deposition of $\mathrm{WO}_{3}$ by the above mentioned precursor combinations is investigated in the range of 250-375 ${ }^{\circ} \mathrm{C}$ proving ALD growth at temperatures $275-325^{\circ} \mathrm{C}$. WOCl $4+\mathrm{H}_{2} \mathrm{O}$ was evaluated for $\mathrm{WO}_{3}$ deposition. The observed surface sensitive growth resulted in limited film growth on selected substrates. The process of lanthanum tungstate deposition was optimized with respect to control of stoichiometry and 0.9 and $1.2 \mu \mathrm{m}$ thick films were deposited on $\mathrm{MgO}$ and Pd for cross-plane and in-plane impedance spectroscopy measurements, respectively. Due to short-circuiting of films on Pd after heat treatment, an alternative deposition procedure was devised which reduced short-circuiting significantly. The films show primarily ionic conductivity under wet conditions. Oxide ions are the dominating conductors above $650{ }^{\circ} \mathrm{C}$, while protons become more dominant at lower temperatures. There is a significant contribution from n-type electronic conductivity in highly reducing atmospheres.

\section{Introduction}

Proton conducting materials are important in energy related applications, such as electricity generation in proton conducting fuel cells (PCFC), $\mathrm{H}_{2}$ generation in steam electrolysers, and as membranes for $\mathrm{H}_{2}$ gas separation. The proton conducting lanthanum tungstate (LWO), previously known as $\mathrm{La}_{6} \mathrm{WO}_{12}$ (ref. 1-3) and recently reformulated to $\mathrm{La}_{28-x} \mathrm{~W}_{4+x} \mathrm{O}_{54+\delta} \mathrm{V}_{2-\delta}(0.74<x$ $<1.08),{ }^{4,5}$ is a promising candidate for application in both PCFCs and $\mathrm{H}_{2}$ permeable membranes. At intermediate temperatures, LWO has a high proton conductivity and negligible electronic conductivity below $750{ }^{\circ} \mathrm{C}\left(3 \times 10^{-3} \mathrm{~S} \mathrm{~cm}^{-1}\right.$ at $\left.750{ }^{\circ} \mathrm{C}\right) .{ }^{3,6,7}$ At temperatures above $800{ }^{\circ} \mathrm{C}$, in a reducing or oxidizing atmosphere, the material exhibits mixed ionic and electronic conductivity., ${ }^{3,7}$ A high $\mathrm{H}_{2}$ permeability of $0.14 \mathrm{~mL}$ $\min ^{-1} \mathrm{~cm}^{-2}$ (ref. 8 and 9) has been measured in an asymmetric LWO membrane at $1000{ }^{\circ} \mathrm{C}$, confirming the possibility for the application of LWO as a $\mathrm{H}_{2}$ permeable membrane. LWO has also shown high chemical stability in $\mathrm{CO}_{2}$-rich and sulphurcontaining atmospheres, ${ }^{9}$ high mechanical stability ${ }^{\mathbf{1 0}}$ as well as a thermal expansion coefficient of $\sim 11-12 \times 10^{-6} \mathrm{~K}^{-1}$ (ref. 11-13), making it compatible with device manufacturing. Chemical compatibility with established cathode materials

Centre for Materials Science and Nanotechnology (SMN), Department of Chemistry, University of Oslo, P.O. Box 1033 Blindern, N-0315 Oslo, Norway. E-mail: kristin. bergum@smn.uio.no

$\dagger$ Electronic supplementary information (ESI) available: Representative Nyquist plots, system descriptions and isothermal conductivity measurements. See DOI: $10.1039 / \mathrm{c} 4 \mathrm{ta} 03359 \mathrm{k}$ such as $\mathrm{La}_{0.7} \mathrm{Sr}_{0.3} \mathrm{MnO}_{3-\delta}, \mathrm{La}_{0.75} \mathrm{Sr}_{0.25} \mathrm{Cr}_{0.5} \mathrm{Mn}_{0.5} \mathrm{O}_{3-\delta}$ (ref. 13) and $\mathrm{Pr}_{2} \mathrm{NiO}_{4}$ (ref. 14) has also been demonstrated.

For both fuel cell and hydrogen membrane applications, the proton-conducting electrolyte should be as thin as possible while still retaining its pin-hole free character. Atomic Layer Deposition (ALD) is a thin film deposition technique that inherently creates uniform, pin-hole free films even on geometrically complex surfaces. It is therefore perfectly suited for deposition of membranes and electrolytes. The film thickness is highly controllable by ALD in the low nm range, opening up for designs where thin membranes can be used to realize high fluxes at lower temperatures. This is a major advantage, as it allows the application of materials which traditionally would be regarded too resistive. The application of thin film designs does, however, introduce challenges with respect to mechanical instability, possible faster degradation, and higher overall leak currents. Such effects have to be taken into consideration in designing new electrolytes. An alternative approach to realization of proton-conducting membranes is to take advantage of the inherent capability of the ALD method to coat evenly on $3 \mathrm{D}$ substrates while still retaining the same quality of the films. The ALD technique can therefore be implemented as a subsequent step to traditional techniques in order to cover any remaining pin-hole on an already established electrolyte or a $\mathrm{H}_{2}$-permeable membrane.

It may be challenging to obtain the target accurate stoichiometry during deposition of complex oxides by the ALD technique. Such materials are typically prepared by combining two or more binary oxide processes sequentially. ${ }^{15}$ The amount of 
material deposited by each binary ALD cycle is process dependent and will often be affected by the surface chemistry of the preceding cycle. In the current work, we combine processes for deposition of the binary oxides, $\mathrm{La}_{2} \mathrm{O}_{3}$ and $\mathrm{WO}_{3}$, to obtain films within the $\mathrm{La}-\mathrm{W}-\mathrm{O}$ system. Deposition of $\mathrm{La}_{2} \mathrm{O}_{3}$ is previously well-known and is summarized in a recent comprehensive review $^{16}$. There are, comparably, limited reports on deposition of $\mathrm{WO}_{3}$ by ALD. ${ }^{17-19} \mathrm{We}$ currently expand and report on novel attempts and routes for deposition of $\mathrm{WO}_{3}$.

The main aim of the current work is to demonstrate the feasibility of using ALD for deposition of proton conducting oxide materials within the relevant $\mathrm{La}: \mathrm{W}$ molar range of 5.3$5.7: 1$ (ref. 5). The second target is to reliably measure the protonic conductivity by impedance spectroscopy, a task which frequently encounters major challenges, mostly due to formation of cracks or delamination in either films or contacts.

\section{Experimental}

All films were deposited using an F120-SAT research - type ALD reactor (ASM Microchemistry) using a combination of different processes for formation of tungsten and lanthanum oxides. The lanthanum oxide process was based on $\mathrm{La}(\text { thd })_{3}$ and ozone, according to the procedure described by Nieminen et $a .^{20}$ $\mathrm{La}$ (thd $)_{3}$ was sublimed inside the reactor at $180{ }^{\circ} \mathrm{C}$ and introduced into the reaction chamber using inert gas valves. Ozone was produced by using a BMT $803 \mathrm{~N}$ from OSTI inc, with oxygen from an ATF Oxygen Concentrator Module from Sequal Technologies. Tungsten oxides were deposited using either a combination of $\mathrm{WOCl}_{4}$ and $\mathrm{H}_{2} \mathrm{O}$ or $\left({ }^{t} \mathrm{BuN}\right)_{2}\left(\mathrm{Me}_{2} \mathrm{~N}\right)_{2} \mathrm{~W}$ (hereafter termed $\mathrm{BMW}$ ) and $\mathrm{H}_{2} \mathrm{O} . \mathrm{H}_{2} \mathrm{O}$ was evaporated from an external container at room temperature. $\mathrm{WOCl}_{4}$ was sublimed inside the reactor at $100-180{ }^{\circ} \mathrm{C}$ using inert gas valves, while the BMW precursor was delivered from an externally heated bubbler using a pressure cycling procedure consisting of filling the 50 $\mathrm{ml}$ bubbler with 0.5 bar of inert gas and delivering this into the reaction chamber. The precursor temperature was subjected to optimization and $60{ }^{\circ} \mathrm{C}$ was applied for the remaining experiments. The inert gas for the reactor was produced using a Schmidlin Sirocco $5 \mathrm{~N}_{2}$ generator $(<99.999 \%)$ at a total rate of $500 \mathrm{sccm}$ resulting in an overall reactor pressure of approximately 4 mbar. The films were deposited on $\mathrm{Si}$ (100), $\mathrm{Mg}(100)$ and Pd. The substrates were cleaned using ethanol and pressurized air and exposed in situ to pulses of $\mathrm{O}_{3}$ prior to the deposition.

The cation atomic composition (cat\%) of the films deposited on Si substrates was determined by X-ray fluorescence (XRF) using a Philips PW2400 XRF and analyzed by the Uniquant program. A J.E Woolham Alpha-SE spectroscopic ellipsometer was used to measure the thickness of the films by modelling the experimental data to a Cauchy function. X-ray diffractograms (XRDs) were measured using a Bruker AXS D8 Discover powder diffractometer equipped with a Ge(111) monochromator providing $\mathrm{CuK} \alpha_{1}$ radiation and recorded using a LynxEye detector. Scanning electron microscopy (Nova NanoSEM 650 from FEI) was used to obtain images of the films. In situ quartz crystal microbalance (QCM) measurements were conducted using home-made holders and recorded using a Maxtek TM400 unit.

Electrical measurements were conducted using two different configurations. For the in-plane measurements, an insulating MgO substrate $\left(1 \times 1 \mathrm{~cm}^{2}\right)$ with the LWO film on top was coated with two stripes of $\sim 500 \mathrm{~nm}$ of Pt separated by $0.5 \mathrm{~mm}$ by sputtering, using a Cressington 308R coating system. For the cross-plane measurements, an electron conducting and $\mathrm{H}_{2}$ permeable dense Pd substrate $(20 \mathrm{~mm}$ diameter, $0.3 \mathrm{~mm}$ thickness) was used. In this case, several contact points of $3 \mathrm{~mm}$ and $\sim 500 \mathrm{~nm}$ thick Pt were coated by sputtering as a counter electrode, and the electrodes that did not short-circuit after annealing were measured. In all cases, Pt grid and wires were attached to either electrode in a 2-point-4-wire setup. Impedance spectra were collected at different temperatures and atmospheres using an impedance analyzer (Novocontrol Alpha A, Novocontrol Technologies) in the $0.1 \mathrm{~Hz}$ to $1 \mathrm{MHz}$ frequency range with an $\mathrm{AC}$ perturbation of $50 \mathrm{mV}$. The thicknesses of the LWO films were approximately $1.2 \mu \mathrm{m}$ on Pd and $0.9 \mu \mathrm{m}$ on $\mathrm{MgO}$. The film and electrode were annealed at $800^{\circ} \mathrm{C}$ for $30 \mathrm{~min}$ prior to the analysis to increase the film crystallinity and electrode adherence.

\section{Results and discussion}

As mentioned in the Introduction, the aim of the current project is to develop thin films in the $\mathrm{La}-\mathrm{W}-\mathrm{O}$ series by combining processes of deposition of binary lanthanum and tungsten oxides. The process of deposition of lanthanum oxide was adopted from the work of Nieminen $e t a^{20}$ and is described in more detail in the section of $\mathrm{La}-\mathrm{W}-\mathrm{O}$ deposition.

\section{$\mathrm{WO}_{3}$ deposition}

The prior experience in deposition of tungsten oxides is relatively limited. We chose to investigate the possible application of $\mathrm{WOCl}_{4}$ and BMW due to their availability and possible simplicity. $\mathrm{WOCl}_{4}$ should on first impression be a simple type of precursor, however, with potential inclusion of chlorine during deposition. While chlorine incorporation is not a challenge with BMW, its current cost is considerably higher. The application of $\mathrm{WCl}_{6}+\mathrm{H}_{2} \mathrm{O}$ as a precursor combination was not considered practical due to likely formation of volatile $\mathrm{WOCl}_{4}$, in a similar manner to that reported for the application of $\mathrm{NbCl}_{5}$ with $\mathrm{H}_{2} \mathrm{O}^{21}$ In the same work by Knapas et al., however, they showed that $\mathrm{NbOCl}_{3}$ can be applied to the formation of films of $\mathrm{Nb}_{2} \mathrm{O}_{5}$. Previous work on deposition of $\mathrm{WO}_{3}$ films by $\mathrm{WF}_{6}$ (ref. 17) has revealed limited film formation due to film etching in the same manner as mentioned above, whereas in situ generated $\mathrm{WO}_{y} \mathrm{~F}_{x}$ proved more successful and a much higher growth rate was obtained. It is therefore likely that the same will apply to the chloride analogue. Previous studies have also shown successful deposition of $\mathrm{WO}_{3}$ using the BMW precursor, ${ }^{18}$ which we have expanded upon in terms of growth temperatures, in addition to further investigation into the ALD/CVD process. 


\section{$\mathrm{WOCl}_{4}$}

The attempts to deposit $\mathrm{WO}_{3}$ using $\mathrm{WOCl}_{4}$ as a cation precursor yielded no growth on Si substrates at first, despite variations of the precursor temperature $\left(100-180{ }^{\circ} \mathrm{C}\right)$, substrate temperature (150-300 $\left.{ }^{\circ} \mathrm{C}\right)$, reactant $\left(\mathrm{H}_{2} \mathrm{O}, \mathrm{O}_{3}, \mathrm{H}_{2} \mathrm{O}+\mathrm{O}_{3}\right)$, and pulsing time (3$25 \mathrm{~s})$. However, signs of deposition were observed when depositing on films of $\mathrm{La}_{2} \mathrm{O}_{3}$ or $\mathrm{Al}_{2} \mathrm{O}_{3}$ on Si substrates.

An in situ QCM analysis, Fig. 1 and 2, was conducted at $275^{\circ} \mathrm{C}$ to obtain some information on the role of the substrate during deposition, specifically on $\mathrm{La}_{2} \mathrm{O}_{3}$. A thin layer of $\mathrm{WO}_{3}$ was deposited on the QCM crystal as a nucleation layer using 20 cycles of the $\mathrm{BMW}+\mathrm{H}_{2} \mathrm{O}$ process described later. The thickness of $\mathrm{WO}_{3}$ was estimated from the $\mathrm{WO}_{3}$ growth rates to be less than a monolayer (1.6 ̊), leaving the Au surface of the QCM only partially covered. No film was observed when $\mathrm{WOCl}_{4}+\mathrm{H}_{2} \mathrm{O}$ were pulsed directly on this surface (Fig. 1a and 2e). Interestingly, while no growth was seen when a long wait time was added between deposition of the nucleation layer and the $\mathrm{WOCl}_{4}+$ $\mathrm{H}_{2} \mathrm{O}$ process, some film formation was detected when pulsing $\mathrm{WOCl}_{4}+\mathrm{H}_{2} \mathrm{O}$ directly after the $\mathrm{BMW}+\mathrm{H}_{2} \mathrm{O}$ process (Fig. 2c). These results were reproducible. Thereafter, a thin layer of $\mathrm{La}_{2} \mathrm{O}_{3}(13 \AA)$ was deposited using 40 cycles of the $\mathrm{La}$ (thd $)_{3}+\mathrm{O}_{3}$ process before the $\mathrm{WO}_{3}$ nucleation layer and the $\mathrm{WOCl}_{4}+\mathrm{H}_{2} \mathrm{O}$ process was repeated. This resulted in formation of a limited amount of material. The growth rate after an initiation period of a few cycles was reasonably high but non-linear (Fig. 1), before tapering off to a very low but linear growth rate within the range studied (Fig. 2d). While the growth did not cease during the limited number of cycles applied in the QCM measurements, prolonging the exposures of the $\mathrm{WOCl}_{4}+\mathrm{H}_{2} \mathrm{O}$ pair on $\mathrm{La}_{2} \mathrm{O}_{3}$ from 1000 to 3000 cycles did not reveal any additional film formation. A similar experiment on $\mathrm{Al}_{2} \mathrm{O}_{3}$, where the number of cycles on the $\mathrm{Al}_{2} \mathrm{O}_{3}$ film increased from 1000 to 2500, gave the same negative result. The film formation was limited to less than two nanometers. An XRF study of the deposited film revealed a significant amount of chlorine in the films deposited

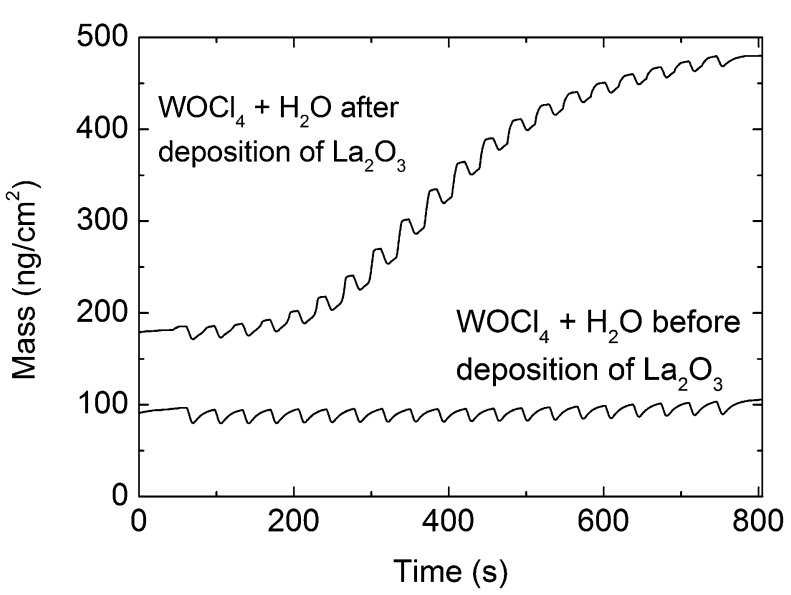

Fig. 1 QCM analysis of variations in mass during deposition of $\mathrm{WOCl}_{4}$ with and without a layer of $\mathrm{La}_{2} \mathrm{O}_{3}$ on the QCM crystal. In both cases, a $1.6 \AA$ layer of $\mathrm{WO}_{3}$ was initially deposited using the $\mathrm{BMW}+\mathrm{H}_{2} \mathrm{O}$ process described in the text.

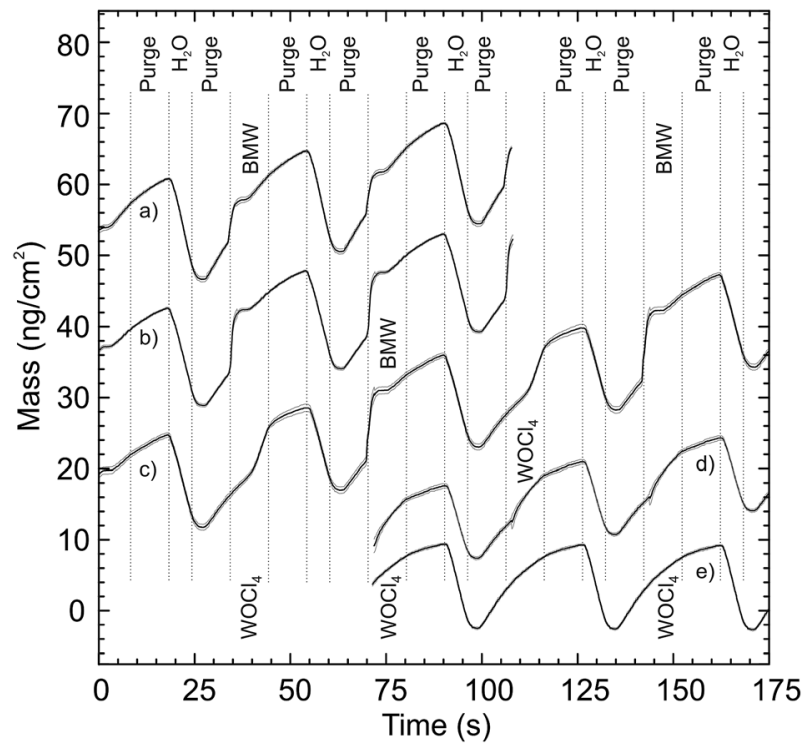

Fig. 2 In situ QCM analysis of longer pulsing sequences (10 s/10 s for all pulse/purge) of different combinations of the $\mathrm{WOCl}_{4}+\mathrm{H}_{2} \mathrm{O}$ and $\mathrm{BMW}+\mathrm{H}_{2} \mathrm{O}$ processes. The graphs shown from top: (a) $\mathrm{BMW}+\mathrm{H}_{2} \mathrm{O}$ process without the initial $\mathrm{La}_{2} \mathrm{O}_{3}$ layer, (b) $\mathrm{BMW}+\mathrm{H}_{2} \mathrm{O}$ with the initial $\mathrm{La}_{2} \mathrm{O}_{3}$ layer, (c) $\left[\mathrm{BMW}+\mathrm{H}_{2} \mathrm{O}\right]+\left[\mathrm{WOCl}_{4}+\mathrm{BMW}\right]$ process without the initial $\mathrm{La}_{2} \mathrm{O}_{3}$ layer, (d) $\mathrm{WOCl}_{4}+\mathrm{H}_{2} \mathrm{O}$ process with the initial $\mathrm{La}_{2} \mathrm{O}_{3}$ layer, (e) $\mathrm{WOCl}_{4}+\mathrm{H}_{2} \mathrm{O}$ process without the initial $\mathrm{La}_{2} \mathrm{O}_{3}$ layer. The QCM data represent an average of 16 subsequent cycles, and the standard deviation from this procedure is shown as grey lines for all sequences.

on $\mathrm{La}_{2} \mathrm{O}_{3}$ resulting in near equiatomic compositions of $\mathrm{W}$ and $\mathrm{Cl}$ (54 at\% $\mathrm{Cl}$ when considering only $\mathrm{Cl}$ and $\mathrm{W}$, excluding the $\mathrm{La}$ and $\mathrm{O}$ content). Chlorine was, however, not detected in the films deposited on $\mathrm{Al}_{2} \mathrm{O}_{3}$.

To conclude, $\mathrm{WO}_{3}$ appears to grow on the surfaces of selected substrates, however, the growth is severely limited as $\mathrm{WO}_{3}$ appears not to grow on itself. The $\mathrm{WOCl}_{4}+\mathrm{H}_{2} \mathrm{O}$ process was not pursued further due to limited incorporation of $\mathrm{W}$ and notable contents of $\mathrm{Cl}$ in the deposited films.

\section{BMW}

The applicability of the $\mathrm{BMW}+\mathrm{H}_{2} \mathrm{O}$ precursor pair for deposition of $\mathrm{WO}_{3}$ was thereafter investigated. The temperature of the precursor was varied from room temperature to $70{ }^{\circ} \mathrm{C}$, using a substrate temperature of $275^{\circ} \mathrm{C}$ and a pulsing sequence of $3 \mathrm{~s}$ BMW, 3 s purge, $3 \mathrm{~s} \mathrm{H}_{2} \mathrm{O}$, and $3 \mathrm{~s}$ purge. The growth rates are shown in Fig. 3. Tests proved that the vapor pressure of the BMW precursor was sufficiently high for complete saturation at a precursor temperature of $60{ }^{\circ} \mathrm{C}$ with the current set-up. This temperature was therefore chosen for all further deposition steps. Lower precursor temperatures were not adopted, although possible, due to the wish to be well within a regime of ALD growth combined with possibilities of later reducing the pulsing time. The pulsing parameters were verified for saturative conditions by simple variations, and were utilized in the remaining experiments for growth of pure $\mathrm{WO}_{3}$.

In situ QCM analysis of the BMW process, Fig. 2a and b, shows a slightly surface enhanced growth on $\mathrm{La}_{2} \mathrm{O}_{3}$ relative to 


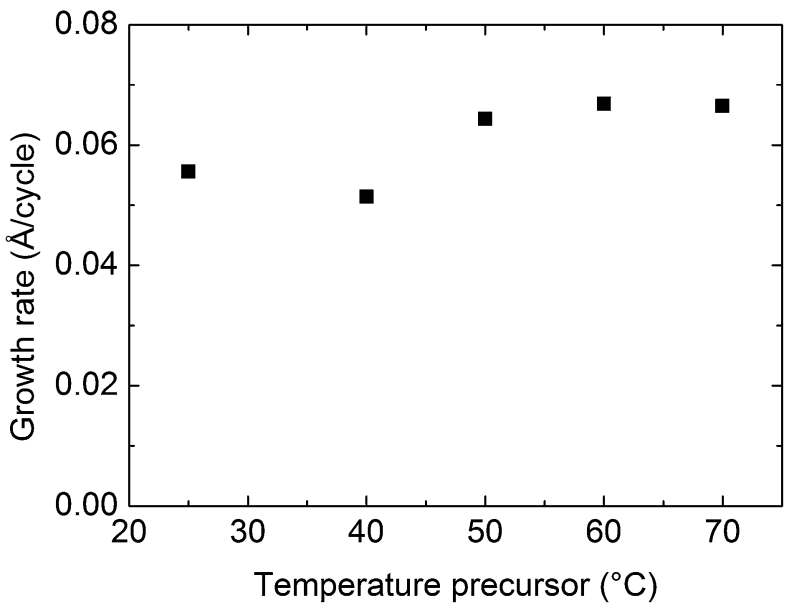

Fig. 3 Growth rate of $\mathrm{WO}_{3}$ from the $\mathrm{BMW}+\mathrm{H}_{2} \mathrm{O}$ process at $275^{\circ} \mathrm{C}$ as a function of the $\mathrm{BMW}$ precursor temperature using a pulsing sequence of $3 \mathrm{~s} B M W, 3 \mathrm{~s}$ purge, $3 \mathrm{~s} \mathrm{H}_{2} \mathrm{O}$, and $3 \mathrm{~s}$ purge.

the pure substrate. The slope per cycle increased from 5.0 to 6.6 $\mathrm{ng} \mathrm{cm}^{-2}$, averaged over 20 cycles. Comparing the two QCM recordings, it appears that the increase in the growth rate stems from a larger uptake of the BMW precursor, while the decrease of mass during the water pulse remains nearly the same. It is likely that the decrease in mass observed in the QCM data is dominated by temperature changes brought about by the water pulse itself, making the data unreliable for analyzing the leaving groups. We can therefore only conclude with a higher density of BMW precursor during its pulse.

The growth rate of $\mathrm{WO}_{3}$ as a function of deposition temperature was investigated in the range of 250 to $375{ }^{\circ} \mathrm{C}$, as presented in Fig. 4. No growth was observed at $250{ }^{\circ} \mathrm{C}$ while a steadily increasing ALD-type growth was found for deposition temperatures from 275 to $325{ }^{\circ} \mathrm{C}$. CVD-type growth was present at and above $350{ }^{\circ} \mathrm{C}$.

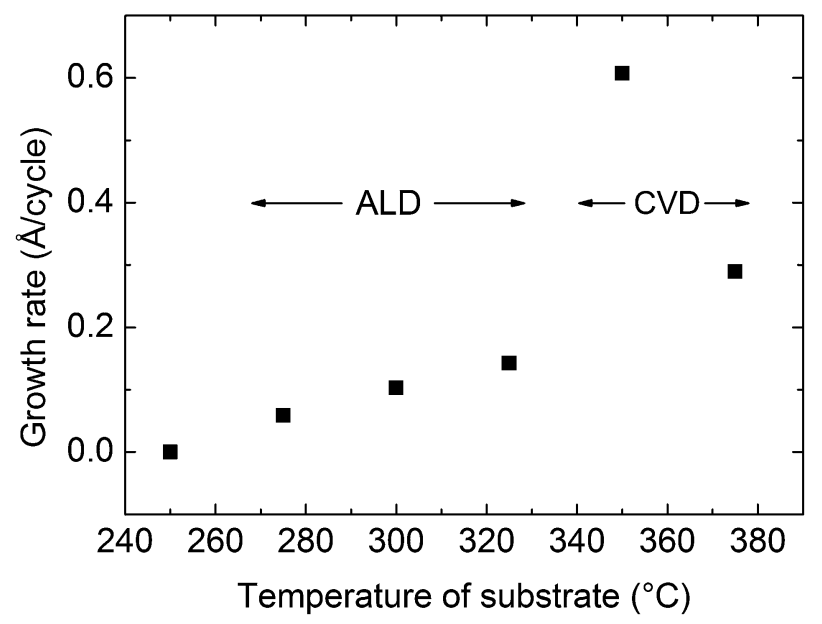

Fig. 4 Growth rate of $\mathrm{WO}_{3}$ as a function of deposition temperature for the BMW $+\mathrm{H}_{2} \mathrm{O}$ process using a pulsing sequence of $3 \mathrm{~s} \mathrm{BMW,} 3 \mathrm{~s}$ purge, $3 \mathrm{~s} \mathrm{H}_{2} \mathrm{O}$ and $3 \mathrm{~s}$ purge.
The CVD-type growth was observed as increased film thickness on extended pulsing time, and by achieving film growth by pulsing of only BMW. Similar tests at $325^{\circ} \mathrm{C}$ proved clearly the growth of the ALD-type as no change in the film thickness occurred with increasing pulsing time and no growth was observed by pulsing only BMW. It should be noted, however, that the CVD deposition of $\mathrm{WO}_{3}$ was remarkably uniform and reproducible.

$\mathrm{XRD}$ analysis revealed all as-deposited $\mathrm{WO}_{3}$ films to be amorphous. RTP annealing caused crystallization of a multitude of $\mathrm{WO}_{3}$ phases at $600{ }^{\circ} \mathrm{C}$.

\section{La-W-O deposition}

The La-W-O system was investigated by combining the deposition processes for $\mathrm{La}_{2} \mathrm{O}_{3}$ and $\mathrm{WO}_{3}$. The number of La cycles $\left[\mathrm{La}(\text { thd })_{3}+\mathrm{O}_{3}\right]$ between each $\mathrm{W}$ cycle $\left[\mathrm{BMW}+\mathrm{H}_{2} \mathrm{O}\right]$ was varied from 10 (91 pulse\%) to 17 (94.5 pulse\%). The pulse and purge parameters used for this investigation were higher than those sufficient for saturation and ensured ALD growth, and were set at $3 / 6 / 3 / 10 \mathrm{~s}$ for $\mathrm{La}_{2} \mathrm{O}_{3}$ and $5 / 5 / 3 / 5 \mathrm{~s}$ for $\mathrm{WO}_{3}$. In particular, the BMW precursor appears to react strongly with any remaining ozone from the La-cycle, and an extra purge of $60 \mathrm{~s}$ was used before introducing the BMW precursor.

The average growth rate increases with La-content as seen in Fig. 5 . This is expected due to the higher growth rate of $\mathrm{La}_{2} \mathrm{O}_{3}$ as compared to $\mathrm{WO}_{3}$. The observed growth rates were, however, lower than a direct combination of the growth rates of the binary oxides. As discussed previously, a surface enhanced growth of $\mathrm{WO}_{3}$ is seen when deposited on $\mathrm{La}_{2} \mathrm{O}_{3}$. Therefore, these results suggest that the growth of $\mathrm{La}_{2} \mathrm{O}_{3}$ is surface inhibited when deposited on $\mathrm{WO}_{3}$.

The correlation between the pulsed and the deposited La : W composition was further investigated, as presented in Fig. 6. It appears that a La-pulsing between 91.3 and $92.4 \%$ gives products within the composition range for the proton conducting LWO phase. These correspond to pulsing ratios of $10.5: 1$ and

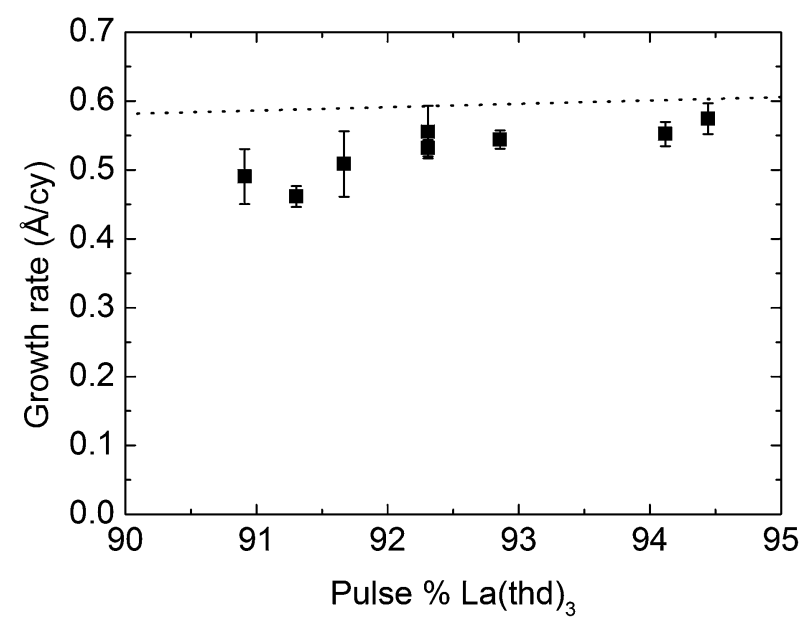

Fig. 5 Growth rate of $\mathrm{La}-\mathrm{W}-\mathrm{O}$ films as a function of the La-pulse percentage using the precursor combinations $x\left[\mathrm{La}(\text { thd })_{3}+\mathrm{O}_{3}\right]+[\mathrm{BMW}$ $\left.+\mathrm{H}_{2} \mathrm{O}\right]$. 


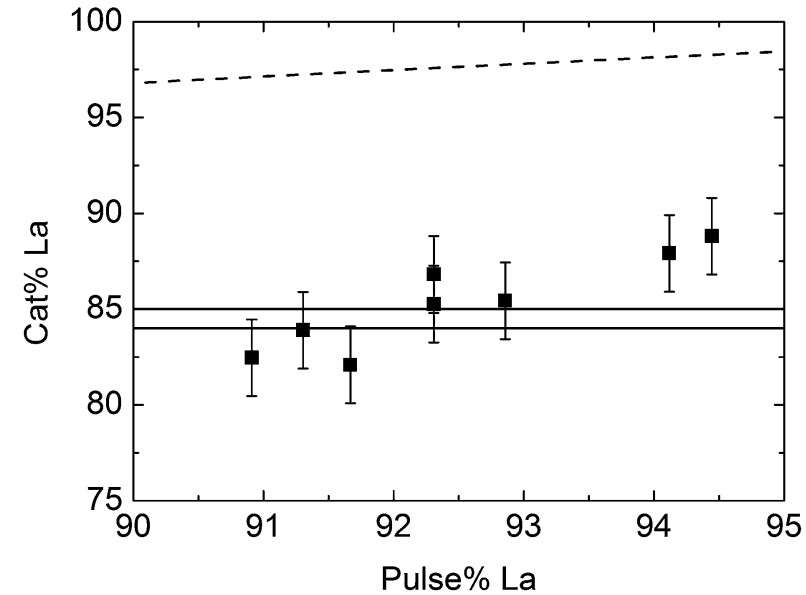

Fig. 6 Deposited content of La cat\% as a function of the La-pulse\%. The target compositions are located in the interval $84-85 \% \mathrm{La}$. The dashed line indicates the calculated compositions on the basis of growth rates of the binary oxides.

$12: 1$, where $10.5: 1$ is achieved by alternating $10: 1$ with $11: 1$. The compositional interval for achieving the proton conducting phase is very small, and the experimental uncertainties in both sample acquisition and analysis are challenging. RBS measurements were performed on selected samples, although outside the pulsing range in Fig. 6. These differ with approximately 2-4 cat\% points from the XRF values. Repeated deposition cycles lead to variations in the order of up to 2 cat\%.

As an additional note, the exact relationship between the pulsed and deposited composition depends also on the ozone concentration. Initial attempts using a generator providing a lower ozone concentration (OT-020 from Ozone Technology, using $>99.9 \% \mathrm{O}_{2}$ ) gave the desired composition at a La-pulse $\%$ of approximately $94 \%$ as compared to approximately 92 pulse $\%$ for the current case. This issue was not subject to further studies.

The expected correlation between pulsed and deposited composition can be calculated on the basis of the individual growth rates and densities of the binary oxides, and is marked with the dashed line in Fig. 6. Our LWO films appear to contain more $\mathrm{W}$ than expected from the individual growth rates. As previously discussed, deposition of $\mathrm{WO}_{3}$ on $\mathrm{La}_{2} \mathrm{O}_{3}$ films indicated a surface enhanced growth of $\mathrm{WO}_{3}$ on $\mathrm{La}_{2} \mathrm{O}_{3}$, while $\mathrm{La}_{2} \mathrm{O}_{3}$ deposition experiences a surface inhibited growth on $\mathrm{WO}_{3}$, which is in accordance with these findings.

\section{$\mathbf{L a}_{28-x} \mathrm{~W}_{4+x} \mathrm{O}_{54+\delta} \mathbf{v}_{2-\delta}$ deposition for electrical measurements}

Pulsing of $91.4 \% \mathrm{La}(\mathrm{thd})_{3}$ cycles (pulsing relationship $10.67: 1$ ) gave films close to the LWO54 composition (5.4:1 ratio for La : W molar ratio). This pulsing ratio was achieved by alternating the macrocycles $10: 1$ and $11: 1$ in a $1: 2$ ratio.

A $0.9 \mu \mathrm{m}$ thick LWO film was deposited on $\mathrm{MgO}$ (100) for inplane measurement and a $1.2 \mu \mathrm{m}$ thick film was deposited on polycrystalline Pd for cross-plane measurements. This thickness of the films allows the resistance through the film to be reliably measured. For Pd substrates, two different methods were used to obtain thick LWO films, termed method 1 (M1) and method 2 (M2). M1 was the same as that for $\mathrm{MgO}$ substrates, using continuous ALD deposition, only stopping the reactor to refill the $\mathrm{La}$ (thd) $)_{3}$ precursor every $22 \mathrm{~h}$. With $\mathrm{M} 2$, $40 \mathrm{~nm}$ LWO films were initially deposited on the Pd substrates by ALD and heat treated at $850{ }^{\circ} \mathrm{C}$ for $30 \mathrm{~min}$ in air. These were subsequently used as substrates for further deposition of approximately $1.16 \mu \mathrm{m}$ of continuous LWO deposition as in the first method. The second method was established to attempt avoiding cracking and short-circuiting of the film during measurements.

The SEM images in Fig. 7 of the as-deposited crystalline LWO films show smooth and crack-free films, appearing to be pinhole-free (Fig. 7a and b). After annealing for $30 \mathrm{~min}$ at $850{ }^{\circ} \mathrm{C}$, the films show an increase in roughness at high magnifications (Fig. 7c and d). The films on $\mathrm{MgO}$ maintained their pinhole-free character, but cracks of approximately $1 \mu \mathrm{m}$ width appeared in the film deposited on Pd using M1 (Fig. 7e). Cracks also appeared after heat treatment using M2, however, the separation between the cracks was much larger than for M1 (Fig. 7f).

All Bragg reflections of both as-deposited and annealed LWO films were ascribed to the proton-conductive fluorite-type phase or to the substrate/deposited contacts when deposited on Pd or

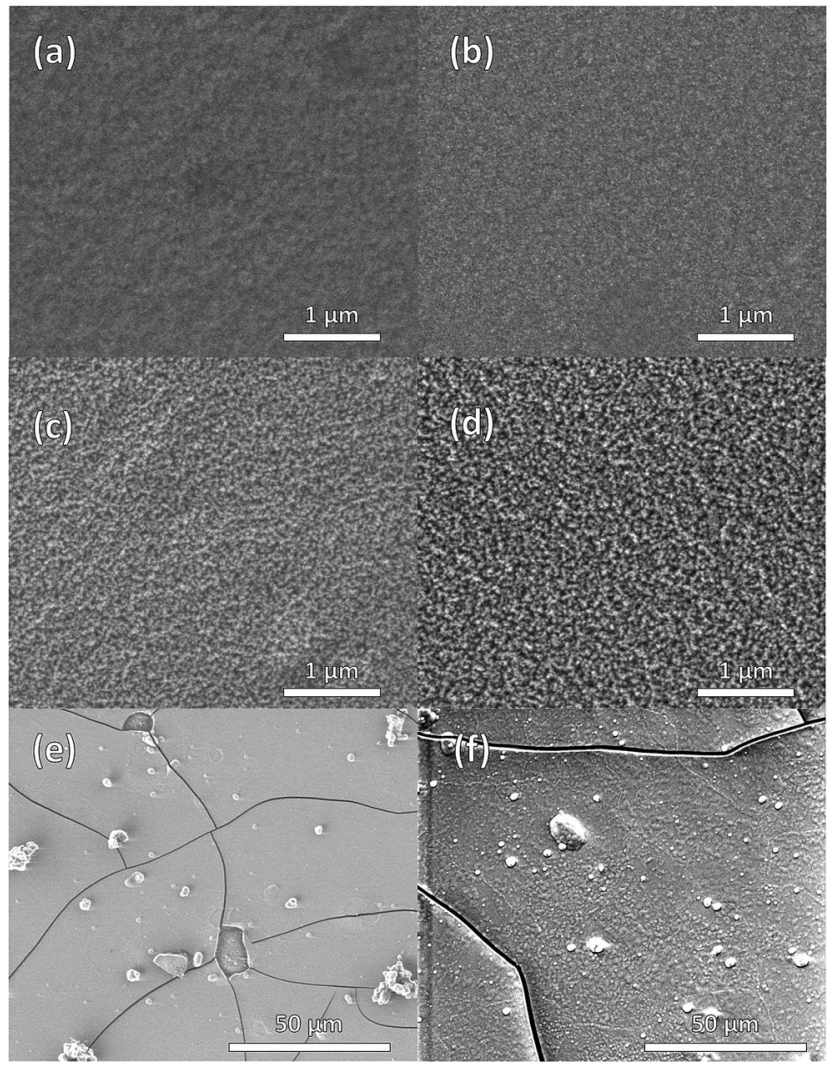

Fig. 7 SEM images of (a) as-deposited on Pd, M1 (b) as-deposited on $\mathrm{MgO}, \mathrm{M1}$ (c) annealed for $30 \mathrm{~min}$ at $850^{\circ} \mathrm{C}$ on Pd, M1 (d) annealed for 30 min at $850^{\circ} \mathrm{C}$ on $\mathrm{MgO}, \mathrm{M} 2$ (e) annealed for $30 \mathrm{~min}$ at $850^{\circ} \mathrm{C}$ on $\mathrm{Pd}$, M1 (f) LWO-3 on Pd after annealing for $30 \mathrm{~min}$ at $850^{\circ} \mathrm{C}$, and electrical measurements with multiple heat cycles up to $650^{\circ} \mathrm{C}$. 
MgO, see Fig. 8. The deposited film shows a strong preferred orientation based on the high intensity of (400) compared to the scarcely visible (222). For a randomly oriented sample, (400) is $44 \%$ of the intensity of (222). After annealing, (222) becomes more intense, and the FWHM of all peaks increases. This is indicative of crystallization of the remaining amorphous LWO material, or recrystallization. The new small crystallites will broaden the peak significantly as well as cause new reflections to appear.

The unit cell dimension $a$ was found to be $11.3 \AA$ and the space group was $F m \overline{3} m .{ }^{12}$ This is larger than the bulk value $a=$ $11.18 \AA$ (ref. 4, 5 and 12). The positions of all reflections shift towards lower $2 \theta$ angles (larger $d$-spacings) upon annealing in air, as is clearly shown in the insets of Fig. 8. This behavior is different than expected since thin films normally tend to relax toward bulk values upon annealing. It is therefore possible that the deposited material is influenced by other chemical parameters, such as hydration or impurities.
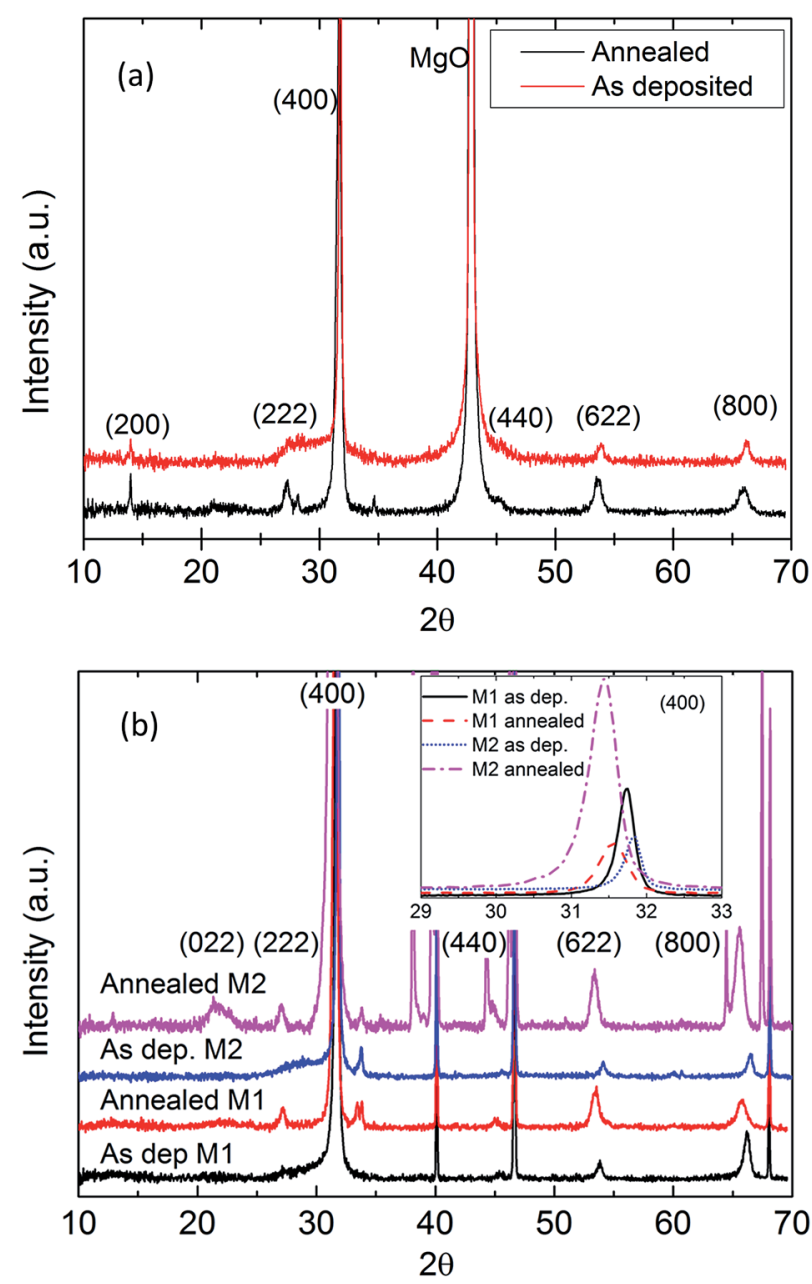

Fig. 8 XRD patterns of LWO films on (a) $\mathrm{MgO}$ and (b) Pd before and after annealing at $850{ }^{\circ} \mathrm{C}$ for 30 minutes. The sharp non-identified peaks are substrate reflections or contact reflections from $\mathrm{MgO}, \mathrm{Pd}$, $\mathrm{PdO}, \mathrm{Ag}$ and $\mathrm{Pt}$, while the identified reflections correspond to the LWO phase. The insets show the most intense reflection (400).

\section{LWO electrical measurements}

The conductivity $\sigma$ as measured both by cross-section and inplane geometry of the films was calculated using the equation:

$$
\sigma=\frac{L}{A} \times \frac{1}{R}
$$

where $L$ is the distance between the electrodes, $R$ is the film resistance, and $A$ is the area of the cross-section of the conducting path. The geometrical factor for the two different configurations differs largely: $A / L_{\text {in-plane }} \sim 10^{-3} \mathrm{~cm} ; A / L_{\text {cross-plane }}$ $\sim 6 \times 10^{2} \mathrm{~cm}$.

Two assumingly identical samples of LWO films deposited on MgO (labeled as LWO-1 and LWO-2) were measured using the in-plane configuration in the temperature range of 650 to $900{ }^{\circ} \mathrm{C}$. The lowest temperature included in these measurements was based on the instrumental resolution for the highest resistive measurements. Representative Nyquist plots (Fig. S1†) and an interpretation of the data are included as the ESI. $\uparrow$ The conductivity of the film includes the contribution from both grain interior and grain boundaries and cannot be separated in this geometry, in accordance with other studies. ${ }^{22,23}$

The variation of the conductivity of the film with temperature under different atmospheres is shown in Fig. 9. LWO-1 was used for a quick assessment of the conducting properties, while LWO-2 was measured to gain further insight into the dominating charge carriers. The data were recorded on cooling.

Fig. 9a (LWO-1) shows that the conductivity in wet Ar is lower than in wet air and in wet $5 \% \mathrm{H}_{2} / \mathrm{Ar}$. This is an indication that some electron hole and electronic conductivity exists in the LWO thin films, under oxidising and reducing conditions, respectively. This is due to an increased concentration of electron holes at high $\mathrm{pO}_{2}$ (eqn (2)) and a higher concentration of electrons at low $\mathrm{pO}_{2}$ (eqn (3)), in accordance with the following defect chemical equations:
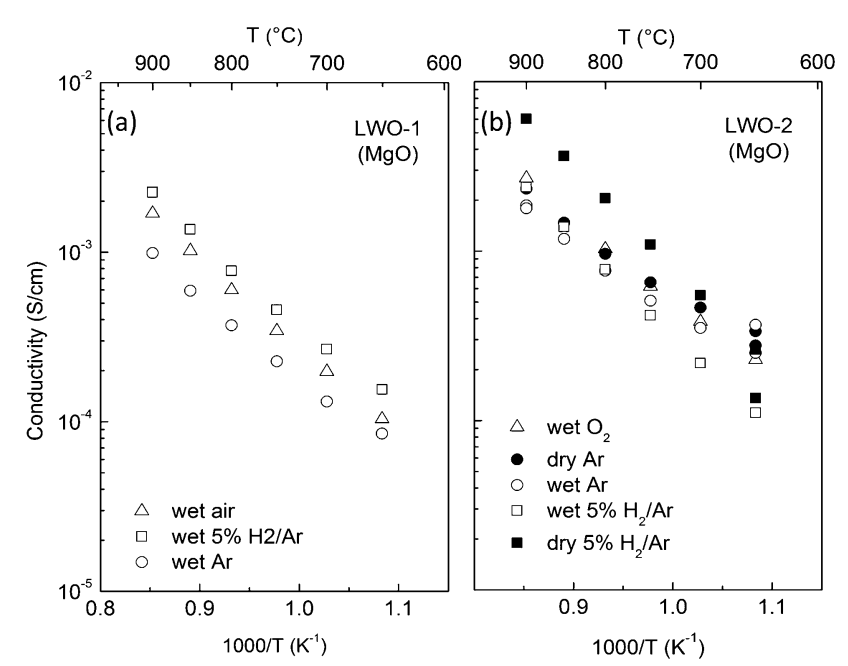

Fig. 9 Variation of the (total $=$ grain interior + grain boundary) conductivity with temperature (a) for LWO-1 and (b) for LWO-2. The list of atmospheres in the legend is in chronological order with respect to conducted data collections (top to bottom). 


$$
\begin{aligned}
& \mathrm{O}_{\mathrm{O}}^{\times}+2 \mathrm{~h}^{\cdot}=\mathrm{v}_{\mathrm{O}}^{\ddot{*}}+1 / 2 \mathrm{O}_{2} \\
& \mathrm{O}_{\mathrm{O}}^{\times}=\mathrm{v}_{\mathrm{O}}^{\cdot}+2 \mathrm{e}^{-}+1 / 2 \mathrm{O}_{2}
\end{aligned}
$$

The activation energy of the conductivity is essentially independent of the atmosphere and about $1 \mathrm{eV}$. A change from wet to dry $\mathrm{Ar}$ (last measurement) at $650{ }^{\circ} \mathrm{C}$ did not show significant variation in the conductivity, suggesting that protons are not the main charge carriers at this temperature.

The conductivities of LWO-2 (Fig. 9b) under wet conditions are quite comparable to those of LWO-1, although the LWO-2 conductivities are, in general, slightly higher. The conductivity of LWO-2 is weakly dependent on both $\mathrm{pO}_{2}$ (under wet conditions), and $p \mathrm{H}_{2} \mathrm{O}$ (in Ar). The variation of the conductivity with $p \mathrm{H}_{2} \mathrm{O}$ was measured isothermally at $650{ }^{\circ} \mathrm{C}$ to clarify the role of protons in LWO thin films deposited by ALD, and is reported in Fig. S2 in the ESI. $\uparrow$ Some protonic conductivity exists at this temperature, but protons are not the main charge carriers.

The activation energy for the conductivity is in the range of 0.8-1 eV (for wet $\mathrm{O}_{2}$ and $\mathrm{Ar}$ atmospheres), while it increases to $\sim 1.1 \mathrm{eV}$ under reducing conditions (see Fig. 9). The conductivity increases significantly from wet to dry $5 \% \mathrm{H}_{2} / \mathrm{Ar}$, suggesting that n-type conductivity becomes more significant due to the lower $p \mathrm{O}_{2}$ under dry reducing conditions.

From the in-plane conductivity measurements of both LWO1 and LWO-2, we may conclude that LWO thin films deposited on $\mathrm{MgO}$ behave mainly as an oxide ion conductor between 650 and $900{ }^{\circ} \mathrm{C}$, with a minor contribution from p-type conductivity under oxidizing conditions, protons under wet conditions, and more significant contribution from n-type electronic conductivity in highly reducing atmospheres.

The third LWO film sample deposited on a conducting Pd substrate (LWO-3) was measured using the cross-plane

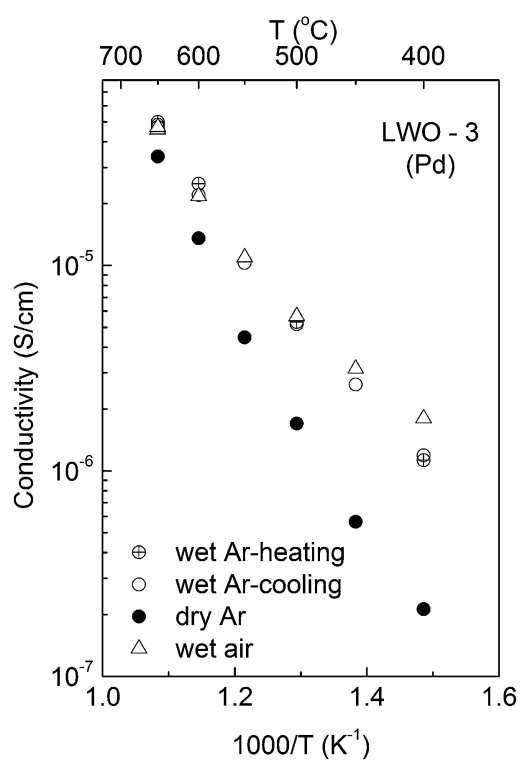

Fig. 10 Variation of the (grain interior) conductivity with temperature for LWO-3. The list of atmospheres in the legend is given in chronological order for conducted measurements. configuration in the temperature range of $400-650{ }^{\circ} \mathrm{C}$. Only samples produced according to method 2 (annealed $40 \mathrm{~nm}$ LWO film on Pd prior to remaining LWO film deposition) could be utilized, as all the samples from method 1 systematically short-circuited after annealing. Representative Nyquist plots (Fig. S3 $\uparrow$ ) and a system description can be found in the ESI. $\dagger$ In this configuration, the highest temperature measured was $650{ }^{\circ} \mathrm{C}$ in order to prevent short-circuiting between the top and bottom electrodes. The contact resistance in the same cell, used for low impedance measurements, ${ }^{24}$ was determined to be $\sim 1 \mathrm{~m} \Omega$ at room temperature, and $\sim 3 \mathrm{~m} \Omega$ at $850{ }^{\circ} \mathrm{C}$. Therefore, it is assumed that the contact resistance in this configuration is negligible.

The variation in conductivity with temperature under different atmospheres for LWO-3 is shown in Fig. 10. The measurements are recorded on cooling, except for the first ramps in Ar, which were taken upon heating. It is remarkable that the conductivities upon heating and cooling in Ar are virtually identical, demonstrating high reproducibility of the results. The conductivity is essentially independent of $\mathrm{pO}_{2}$ from inert to oxidizing conditions, but dependent on $\mathrm{pH}_{2} \mathrm{O}$. The conductivity increases with increasing $p \mathrm{H}_{2} \mathrm{O}$ and the dependence increases with decreasing temperature. This reflects that the concentration of protons and, accordingly, their contribution to the total conductivity, increase with decreasing temperature and increasing water vapor pressure, in accordance with the exothermic hydration reaction:

$$
\mathrm{H}_{2} \mathrm{O}+\ddot{\mathrm{O}_{\mathrm{O}}}+\mathrm{O}_{\mathrm{O}}^{\times}=2 \mathrm{OH}_{\mathrm{O}}^{\cdot}
$$

It is interesting to note that the difference between wet and dry $\mathrm{Ar}$ at $650{ }^{\circ} \mathrm{C}$ corresponds well to the cross-plane measurements. At the lowest temperature measured here, the conductivity is essentially proportional to $\mathrm{pH}_{2} \mathrm{O}^{1 / 4}$, supporting the dominance of proton conductivity at this temperature under wet conditions.

The activation energy for the conductivity of LWO-3 decreases from $\sim 1.1 \mathrm{eV}$ in dry Ar to $\sim 0.5-0.6 \mathrm{eV}$ under wet conditions at the lowest temperatures ( $c f$. Fig. 10). This is in accordance with a change in the dominating conducting species depending on the atmosphere and temperature: under dry conditions or wet conditions and high temperatures, the material is essentially dehydrated. Ionic conductivity is therefore dominated by oxide ions, in accordance with an activation energy of $\sim 1 \mathrm{eV}$. Under wet conditions and at lower temperatures, the LWO film becomes increasingly hydrated, and protons become the main charge carrier. This is in accordance with a lower activation energy $(0.5-0.6 \mathrm{eV})$ and the value expected based on recent literature reports (the activation energy of mobility of protons in LWO56 is determined to be $0.6 \mathrm{eV}) .{ }^{25}$ The conductivity does not change significantly when turning from wet air to wet $5 \% \mathrm{H}_{2} / \mathrm{Ar}$ at $650{ }^{\circ} \mathrm{C}$, although a complete temperature ramp could not be performed due to a short-circuit in the system when cooling from 650 to $600{ }^{\circ} \mathrm{C}$.

From the cross-plane conductivity measurements, we may conclude that the LWO thin film deposited on Pd behaves mainly as an ionic conductor between 650 and $400{ }^{\circ} \mathrm{C}$, with 


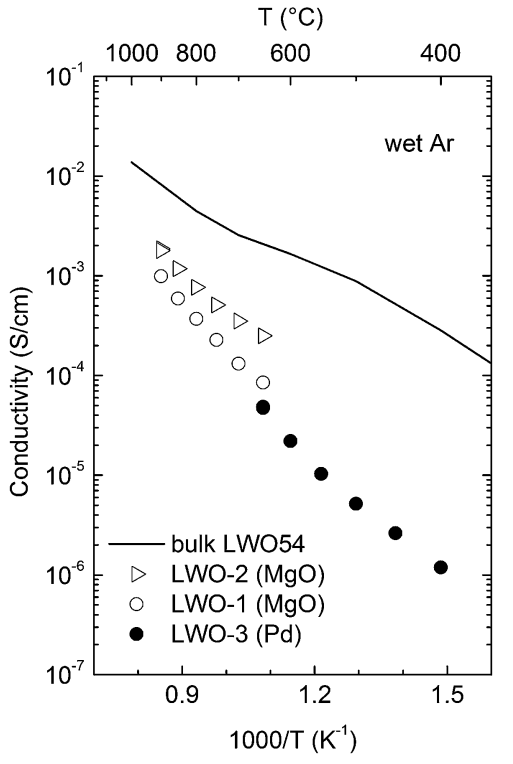

Fig. 11 Comparison of electrical conductivity in wet Ar of ALD grown LWO thin films and bulk LWO54 as reported by Magrasó et al. ${ }^{5}$

increasing dominance of protons under wet conditions at lower temperatures, and with a negligible contribution from electronic defects.

The conductivity characteristics of the LWO thin films are compared in Fig. 11 with bulk data of LWO54. ${ }^{5}$ First, it is interesting to highlight that the measurements of both in-plane and cross-plane measurements are very consistent with each other, essentially reproducing the overall behavior and activation energies. From the combined conductivity ramps, we may conclude that the LWO thin films in wet Ar mainly show ionic conductivity, with protons dominating at the lowest temperatures $\left(\sim 400{ }^{\circ} \mathrm{C}\right)$, and oxide ions at higher temperatures $\left(>650^{\circ} \mathrm{C}\right)$. Although this is in general agreement with the grain interior properties of LWO, the temperature where dehydration occurs is much lower in the thin film, compared to the bulk. This indicates that the hydration reaction described in eqn (2) is less exothermic for the thin film. Another important difference between the film and the bulk material is the magnitude of the conductivity. It is evident from Fig. 11 that the conductivity is one or two orders of magnitude lower at high and low temperatures, respectively. Vøllestad $e t a l .{ }^{26}$ recently reported that LWO thin films deposited on a Pd substrate by pulsed laser deposition exhibited lower conductivities than bulk, however, their values $\left(\sim 3 \times 10^{-4} \mathrm{~S} \mathrm{~cm}^{-1} \text { at } 600{ }^{\circ} \mathrm{C}\right)^{26}$ are higher than those currently reported $\left(\sim 2 \times 10^{-5} \mathrm{~S} \mathrm{~cm}^{-1}\right.$ at $\left.600{ }^{\circ} \mathrm{C}\right)$ for wet conditions.

One may speculate whether the oxygen vacancies in the film are trapped, compared to the situation in the bulk material. A more plausible explanation may be related to doping. From the overall conductivity behavior it seems that a donor doping effect is present in both in-plane and cross-plane measurements: both the oxide ion and protonic conductivity are severely depleted while n-type electronic conductivity is enhanced. It has been reported that tungsten in LWO acts as a self-dopant., ${ }^{4,25}$ The donor doping effect of tungsten has been reported to decrease the ionic conductivity about one order of magnitude, ${ }^{5}$ in a similar manner to that encountered here at high temperatures. This, however, requires further investigation to be resolved.

\section{Conclusions}

Thin films of lanthanum tungstate (LWO) were produced using atomic layer deposition by combining the binary deposition processes of $\mathrm{La}_{2} \mathrm{O}_{3}$ and $\mathrm{WO}_{3}$. The precursor $\mathrm{La}(\text { thd })_{3}$ in combination with ozone was used for deposition of $\mathrm{La}_{2} \mathrm{O}_{3}$. Deposition of $\mathrm{WO}_{3}$ using the cation precursors, $\mathrm{WOCl}_{4}$ and $\left({ }^{t} \mathrm{BuN}\right)_{2}\left(\mathrm{Me}_{2} \mathrm{~N}\right)_{2} \mathrm{~W}(\mathrm{vI})$ (BMW), was investigated, where $\mathrm{WOCl}_{4}$ was found to provide growth on $\mathrm{La}_{2} \mathrm{O}_{3}$ and $\mathrm{Al}_{2} \mathrm{O}_{3}$, but not on itself, and was therefore not useful for LWO deposition. The cation precursor BMW in combination with water gave ALDtype growth between 275 and $325^{\circ} \mathrm{C}$, and was therefore utilized in the LWO deposition. A series of $\mathrm{La}-\mathrm{W}-\mathrm{O}$ films were deposited, for exploring the change in achieved composition with pulsing percentages. Films with La-pulsing percentage between 91.3 and $92.4 \%$ appeared to fall within the composition range for the proton conducting LWO phase, or a pulsed relationship of $10.5: 1$ and $12: 1$ between La(thd $)_{3}$ and BMW.

1.2 and $0.9 \mu \mathrm{m}$ thick crystalline films with a La-pulsing percentage of $91.4 \%$ were deposited on $\mathrm{Pd}$ and $\mathrm{MgO}$, respectively. These were confirmed as the proton-conducting phase of LWO by XRD. The films were pin-hole free as-deposited. The LWO film on Pd cracked during annealing, causing short-circuiting in all cells for electrical characterization. An alternative deposition procedure was therefore devised, where a thin layer of LWO film (40 nm) was deposited on the substrate and subsequently annealed. A $1.16 \mu \mathrm{m}$ LWO film was thereafter deposited on top of the annealed LWO film. This procedure was successful in avoiding short-circuiting of LWO films during electrical measurements, and the electrical properties were reproducibly measured both in cross-plane and in-plane configurations.

The LWO films behave mainly as an oxygen ion conductor at high temperatures, but mainly as a proton conductor at lower temperatures and under wet conditions, with some contributions from p-type conductivity under oxidizing conditions, and a more significant contribution from n-type electronic conductivity in highly reducing atmospheres. The in-plane and cross-plane measurements for films on $\mathrm{MgO}$ and $\mathrm{Pd}$, respectively, are consistent. The magnitude and the temperature dependence of the conductivity in LWO films grown by ALD differ from the bulk values. This may be attributed to internal doping effects.

\section{Acknowledgements}

The authors would like to thank the Department of Geosciences at UiO for use of the XRF equipment, Antje Hoenen for assistance during electrode sputtering, Annett Thøgersen at SINTEF and Susmit Kumar at UiO for SEM images. This work is part of the EMALD (195233) KPN-project, funded by the Research Council of Norway, Protia, Innotech Solar and Baldur Coatings. 


\section{Notes and references}

1 M. Yoshimura and J. F. Baumard, Mater. Res. Bull., 1975, 10, 983-988.

2 T. Shimura, S. Fujimoto and H. Iwahara, Solid State Ionics, 2001, 143, 117-123.

3 R. Haugsrud, Solid State Ionics, 2007, 178, 555-560.

4 A. Magrasó, J. M. Polfus, C. Frontera, J. Canales-Vazquez, L.-E. Kalland, C. H. Hervoches, S. Erdal, R. Hancke, M. S. Islam, T. Norby and R. Haugsrud, J. Mater. Chem., 2012, 22, 1762-1764.

5 A. Magrasó, C. Frontera, D. Marrero-Lopez and P. Nunez, Dalton Trans., 2009, 10273-10283.

6 R. Haugsrud and C. Kjolseth, J. Phys. Chem. Solids, 2008, 69, 1758-1765.

7 A. Magrasó, J. Power Sources, 2013, 240, 583-588.

8 V. Gil, J. Gurauskis, C. Kjolseth, K. Wiik and M. A. Einarsrud, Int. J. Hydrogen Energy, 2013, 38, 3087-3091.

9 S. Escolastico, C. Solis, T. Scherb, G. Schumacher and J. M. Serra, J. Membr. Sci., 2013, 444, 276-284.

10 J. J. Roa, A. Magraso, M. Morales, P. Nunez and M. Segarra, Ceram. Int., 2011, 37, 1593-1599.

11 V. Gil, R. A. Strom, L. J. Groven and M. A. Einarsrud, J. Am. Ceram. Soc., 2012, 95, 3403-3407.

12 A. Magrasó, C. H. Hervoches, I. Ahmed, S. Hull, J. Nordstrom, A. W. B. Skilbred and R. Haugsrud, J. Mater. Chem. A, 2013, 1, 3774-3782.

13 E. Quarez, K. V. Kravchyk and O. Joubert, Solid State Ionics, 2012, 216, 19-24.
14 E. Quarez, Y. Oumellal and O. Joubert, Fuel Cells, 2013, 13, 34-41.

15 O. Nilsen, E. Rauwel, H. Fjellvag and A. Kjekshus, J. Mater. Chem., 2007, 17, 1466-1475.

16 V. Miikkulainen, M. Leskela, M. Ritala and R. L. Puurunen, J. Appl. Phys., 2013, 113, 021301.

17 P. Tägtström, P. Martensson, U. Jansson and J. O. Carlsson, J. Electrochem. Soc., 1999, 146, 3139-3143.

18 R. Liu, Y. J. Lin, L. Y. Chou, S. W. Sheehan, W. S. He, F. Zhang, H. J. M. Hou and D. W. Wang, Angew. Chem., Int. Ed., 2011, 50, 499-502.

19 J. Malm, T. Sajavaara and M. Karppinen, Chem. Vap. Deposition, 2012, 18, 245-248.

20 M. Nieminen, M. Putkonen and L. Niinisto, Appl. Surf. Sci., 2001, 174, 155-165.

21 K. Knapas, A. Rahtu and M. Ritala, Chem. Vap. Deposition, 2009, 15, 269-273.

22 M. Gerstl, E. Navickas, G. Friedbacher, F. Kubel, M. Ahrens and J. Fleig, Solid State Ionics, 2011, 185, 32-41.

23 H. Bae, J. Choi and G. M. Choi, Solid State Ionics, 2013, 236, 16-21.

24 J. Froitzheim, A. Magraso, T. Holt, M. W. Lundberg, H. F. Windisch, R. Berger, R. Sachitanand, J. Westlinder, J. E. Svensson and R. Haugsrud, ECS Trans., 2013, 57, 2187-2193.

25 S. Erdal, L. E. Kalland, R. Hancke, J. Polfus, R. Haugsrud, T. Norby and A. Magraso, Int. J. Hydrogen Energy, 2012, 37, 8051-8055.

26 E. Vøllestad, A. Gorzkowska-Sobas and R. Haugsrud, Thin Solid Films, 2012, 520, 6531-6534. 